\title{
Late onset and persistence of post-traumatic stress disorder symptoms in survivors of critical care
}

\author{
Aaron Khitab MD ${ }^{1}$, John Reid MD FRCPC FCCP², Vern Bennett MD FRCPC1, \\ G Camelia Adams MD MSc FRCPC ${ }^{1}$, Lloyd Balbuena PhD ${ }^{1}$
}

\begin{abstract}
A Khitab, J Reid, V Bennett, GC Adams, L Balbuena. Late onset and persistence of post-traumatic stress disorder symptoms in survivors of critical care. Can Respir J 2013;20(6):429-433.
\end{abstract}

BACKGROUND: Several recent studies have reported that post-traumatic stress disorder (PTSD) is a frequent occurrence in survivors of an intensive care unit (ICU) admission.

OBJECTIVE: To assess the frequency of PTSD symptoms at three and nine months post-ICU admission and examine possible risk factors that predispose to the development of PTSD symptoms.

METHOD: Using the following scales: Davidson Trauma Scale, Impact of Event Scale and the Post-traumatic Symptom Scale, 69 ICU survivors were assessed for PTSD symptoms at three months post-ICU admission. Of the original 69 patients, 37 completed the same questionnaires at the second follow-up at nine months post-ICU admission. Mean symptom levels for avoidance, intrusive thoughts and hyperarousal were calculated, and risk factors for the development of PTSD symptomatology were examined.

RESULTS: Depending on which scale was used, $16 \%$ to $33 \%$ of ICU survivors met the criteria for PTSD at either three or nine months. Younger age and the use of a prescription psychoactive medication at time of ICU admission were both independently associated with a higher risk of developing PTSD symptoms. Interestingly, symptoms of hyperarousal worsened during the follow-up interval for female patients, while they remained constant for males.

CONCLUSION: The frequency of PTSD symptoms was high in patients who survived an admission to the ICU. Depending on sex, symptoms may present and evolve differently. The adoption of screening tools and a multicentre ICU database in Canada is recommended to identify patients who are most at risk.

Key Words: Follow-up studies; Intensive care; Post-traumatic; Stress disorders

\section{L'apparition tardive et la persistance de symptômes de stress post-traumatique chez des survivants des soins intensifs}

HISTORIQUE : Selon plusieurs études récentes, le syndrome de stress post-traumatique (SSPT) est fréquent chez les survivants d'une hospitalisation à l'unité de soins intensifs (USI).

OBJECTIF : Évaluer la fréquence des symptômes du SSPT trois et neuf mois après une hospitalisation à l'USI et examiner les facteurs de risque qui peuvent prédisposer à l'apparition de symptômes de SSPT.

MÉTHODOLOGIE : Au moyen de l'échelle de traumatismes de Davidson, de l'échelle de l'effet de l'incident et de l'échelle de symptômes post-traumatiques, les chercheurs ont évalué 69 survivants de l'USI afin de déterminer s'ils présentaient des symptômes du SSPT trois mois après l'hospitalisation à l'USI. De ce nombre, 37 ont rempli le même questionnaire lors du deuxième suivi neuf mois après l'hospitalisation à l'USI. Les chercheurs ont calculé les taux moyens des symptômes d'évitement, de pensées intrusives et d'hyperexcitation et ont examiné les facteurs de risque d'apparition de symptômes de SSPT.

RÉSULTATS : Selon l'échelle utilisée, de $16 \%$ à $33 \%$ des survivants de l'USI respectaient les critères de SSPT au bout de trois ou neuf mois. Un âge moins élevé et l'utilisation d'un psychotrope sur ordonnance au moment de l'hospitalisation à l'USI s'associaient tous deux de manière indépendante à un plus fort risque de symptômes de SSPT. Fait intéressant, les symptômes d'hyperexcitation s'aggravaient pendant l'intervalle de suivi chez les patients de sexe féminin, mais demeuraient constants chez ceux de sexe masculin.

CONCLUSION : La fréquence de symptômes de SSPT était élevée chez les patients qui avaient survécu à une hospitalisation à l'USI. Selon le sexe, les symptômes peuvent se manifester et évoluer différemment. Il est recommandé d'adopter des outils de dépistage et de créer une base de données multicentrique des USI du Canada pour déterminer les patients les plus vulnérables.
Dost-traumatic stress disorder (PTSD) is an anxiety disorder that occurs following exposure to a traumatic event that is perceived by the individual as seriously threatening to oneself or others (1). The condition is marked by three main clusters of symptoms that can be classified into: intrusive and distressing re-experiencing of the threat; significant avoidance of reminders; and persistent hypervigilence (DSM-IV) (1). A diagnosis of PTSD is made if the symptoms persist for at least one month, with 'acute' PTSD lasting up to three months and 'chronic' PTSD lasting more than three months. Most commonly, the symptoms occur relatively soon after the traumatic event has occurred. However, in rare cases, the onset can be delayed by more than six months (1). PTSD cases are highly prevalent among war veterans, victims of crime or natural disaster, as well as cancer survivors $(2-4)$. In the past decade, several studies (5-7) have reported that admission to an intensive care unit (ICU) also is a risk factor for the development of PTSD symptoms in patients who survive and return to the community. Certainly, an ICU admission has many potential causes of psychological and physiological stress, the first of which is the severity of illness inherent with the admission itself. Furthermore, invasive treatments, such as endotracheal intubation and mechanical ventilation (8), may induce further stress and a sense of helplessness in the patient. Additionally, ICU stay is often accompanied by either continuous or intermittent sedation, as well as the frequent development of sleep disturbances (9) and even frank delirium. Not surprisingly, service delivery characteristics, such as ICU length of stay and the use of invasive procedures, have been reported to predict the occurrence of post-ICU PTSD (10). In addition to these ICU-specific factors, premorbid psychiatric history, substance abuse and previous trauma are also believed to increase the risk of PTSD symptoms after ICU admission $(11,12)$. While this area has generated much recent interest, it remains a relatively novel area of research and more data are needed to help identify which patients are at greatest risk for PTSD. This has important clinical significance because early identification of 'at risk' patients could facilitate early intervention post-ICU discharge to the ward and, in turn, to the community.

Recently, an extensive systematic review by Davydow et al (13) reported the median post-ICU PTSD prevalence to be $22 \%$ when assessed using self-reported scales and $19 \%$ based on clinical interview. Furthermore, two separate studies have addressed the important issue of PTSD symptom evolution over time. The first, a study by 


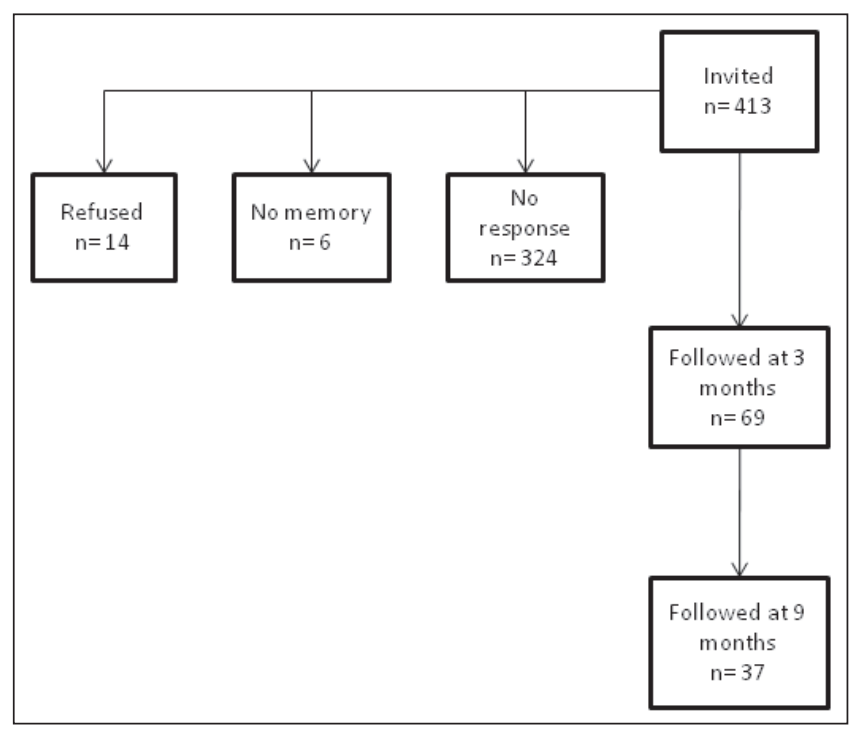

Figure 1) Flow diagram of recruitment and participation

Rattray et al (14), reported that while depression and anxiety decreased over the first year, symptoms of avoidance and intrusion persisted. Toien et al (15) reported that the proportion of patients who experienced an increase in symptoms over time was equal to those who experienced a decrease in symptoms. Accordingly, the authors postulated that a subgroup of ICU patients may exhibit a delayed onset of psychological distress. While risk factors for high levels of PTSD symptoms at a single time point are known (eg, age, sex, pre-existing psychiatric morbidity) (13), factors predicting change in symptom degree over time have not been elucidated.

The three objectives of the present study were: to assess the frequency of PTSD symptoms at three and nine months post-ICU admission; to examine the change over time in each of the DSM-IV PTSD symptom clusters; and to determine the demographic and clinical factors that are related to symptom change over time.

\section{METHODS}

\section{Sample}

The sampling frame consisted of 1066 consecutive admissions to the Royal University Hospital ICU in Saskatoon, Saskatchewan, from March 2008 to March 2009. Exclusion criteria were the following: ICU admission $<24 \mathrm{~h}$; coronary artery bypass graft or valve surgery patients; and hospital mortality. After applying the exclusion criteria, 413 individuals were sent invitations for study participation by mail at three months post-ICU admission. A total of 69 (17\%) individuals returned the consent forms and completed the initial study assessment at three months post-ICU admission. Of the initial 69 participants, 37 (54\%) completed the follow up mail-out questionnaires at nine months (Figure 1).

\section{Dependent variable and covariates}

The first outcome of interest was the proportion of patients meeting PTSD thresholds at three and nine months post-ICU admission. Mean PTSD levels were also examined at both time points. Age, sex, length of stay, primary reason for and number of ICU admissions in the period, and prescribed medications at hospital admission were also evaluated.

\section{Instruments}

PTSD symptoms were assessed using three self-report rating scales: the Davidson Trauma Scale (DTS), the Impact of Event Scale (IES) and the Post-traumatic Symptom Scale (PTSS-10). The DTS (16) is comprised of 17 statements rated on a five-point ( 0 to 4 ) Likert scale. Each statement corresponds to each of the DSM-IV symptoms (17), and is independently rated for frequency and severity of occurrence. The IES is a 15 -item scale that measures subjective distress following a traumatic event (18). It is subdivided into intrusion and avoidance subscales referring to unwanted thoughts and denial of the event, respectively. The IES has been reported to have satisfactory internal consistency, with Cronbach's alpha generally ranging from 0.73 to 0.8819 (18). The DTS has been reported to have excellent internal consistency (20) and, unlike the older IES, the DTS covers all three symptom clusters identified in the DSM-IV: intrusion, avoidance and hyperarousal (16). The IES has subsequently been revised to incorporate a seven-item hyperarousal and re-experiencing subscale and the revised scale (IES-R) correlates strongly with the Clinician Administered PTSD Scale (CAPS) (21). The PTSS-10 was originally designed to measure PTSD among torture and disaster victims but has been adapted for use in the ICU (22). In that study, it had a Cronbach's alpha of 0.93 and a test-retest reliability of 0.89 . Validation studies have been conducted on the DTS (with the Mini International Neuropsychiatric Interview) (23) and the PTSS-10 (with the Structured Clinical Interview for DSM IV [SCID]) (6), with satisfactory results.

\section{Analysis}

Participants $(n=37)$ who were followed and those lost to follow-up $(n=32)$ were first compared according to demographic and clinical characteristics. The PTSD rate was calculated for the entire sample, and then for the subset that provided data at the two time points. In calculating the proportion with likely PTSD, the threshold scores used were 40, 35 and 20 for the DTS, PTSS and IES subscales, respectively, following recommended guidelines $(16,18,22)$. Scores for the three instruments were correlated with one another to determine concordance. In the subset of participants that was followed at both times, the change in DTS subscale scores was analyzed using random intercepts linear regression as implemented in Stata version 12 (StataCorp, USA). The DTS was selected because it conformed to DSM-IV's symptom clusters and has been shown to be effective in evaluating treatment response (23). Age, sex, length of stay and being on medication were examined as predictors.

\section{Ethics}

The study protocol was approved by the University of Saskatchewan Ethics Board and the Saskatoon Health Region.

\section{RESULTS}

Subjects who completed questionnaires at both time points were similar to those who dropped out in terms of age, sex, length of ICU stay and number of ICU admissions. Individuals lost to follow-up were more likely to be on antipsychotic medications compared with those not lost to follow-up $\left(\chi^{2}=4.40 ; \mathrm{P}=0.04\right)$ and were also more likely to have been admitted to ICU for surgery or trauma $\left(\chi^{2}=4.39 ; \mathrm{P}=0.04\right)$ (Table 1). The three different PTSD measures correlated very strongly with one another (range of Pearson's r, 0.85 to 0.91 ; all $\mathrm{P}<0.01$ ). Younger age was associated with more severe psychopathology in all scales. Length of stay did not correlate with any of the PTSD scales.

In the full sample, the proportion with clinically relevant symptoms ranged from $16 \%$ to $33 \%$ for the different instruments at three months post-ICU admission and did not vary according to sex (Table 2). In the subset of subjects who were evaluated at both three and nine months, the proportion of individuals with clinically relevant symptoms increased in all PTSD scales except for IES Intrusion. However, the change in proportion did not reach statistical significance due to the low number of subjects. Similarly, the mean for each subscale also increased at nine months, except for IES Intrusion, but once again did not reach statistical significance (Table 3).

In the longitudinal model, there was a significant sex $\times$ time interaction (beta $=7.76$ [95\% CI 2.55 to 12.97]) for DTS Hyperarousal (Figure 2). Neither the sex $\times$ time interaction nor the main effect of time was significant for DTS Avoidance/Numbing and DTS Intrusion. In all symptom clusters, higher age predicted less severity, and a use of any of the four psychoactive medications assessed was associated with greater severity. 
TABLE 1

Demographic and clinical characteristics according to follow-up status

\begin{tabular}{lccc}
\hline Characteristic & $\begin{array}{c}\text { Lost to follow-up } \\
(\mathbf{n}=\mathbf{3 2})\end{array}$ & $\begin{array}{c}\text { Followed } \\
(\mathbf{n}=37)\end{array}$ & $\mathbf{P}$ \\
\hline Male sex, n (\%) & $23(72)$ & $24(65)$ & 0.53 \\
Age at discharge, years, mean & 56.31 & 55.57 & 0.41 \\
Length of stay, days, mean & 3.75 & 3.20 & 0.32 \\
Category of admission & & & \\
$\quad$ Medical & 7 & 17 & 0.04 \\
$\quad$ Surgical/trauma & 25 & 20 & \\
Intensive care unit admissions & & & \\
1 & 29 & 33 & 1.00 \\
2 & 3 & 4 & \\
Medications taken & & & \\
Mood stabilizers & 1 & 4 & 0.37 \\
Antidepressants & 10 & 8 & 0.31 \\
Antipsychotics & 4 & 0 & 0.04 \\
Benzodiazepines & 5 & 1 & 0.08 \\
\hline
\end{tabular}

Data presented as $n$ unless otherwise indicated

\section{DISCUSSION}

The results indicate that individuals admitted to the ICU are at risk for developing PTSD symptoms. The longitudinal design of the present study demonstrated that PTSD symptoms have a high rate of chronicity (lasting $>3$ months). In fact, the proportion of patients with clinically relevant PTSD symptoms remains unchanged up to nine months post-ICU admission. More specifically, assessment according to DTS scores, avoidance and intrusion symptoms remained the same over the sampling period. Interestingly, although hyperarousal levels remained the same among men, scores actually increased for women at nine months compared with three months post-ICU admission. The data also indicate that younger age and the use of psychoactive medication at the time of ICU admission were associated with higher levels of PTSD symptoms in all three symptom clusters.

The findings are consistent with those found by other authors insomuch as the rate and intensity of PTSD symptomatology were unchanged over the first year post-ICU admission (14,24-26). The current study supports the call for greater awareness of the risk for developing PTSD symptoms in survivors of an ICU admission as well as for an understanding that such symptomatology may be long lasting. While assessments using a gold standard, such as SCID or CAPS, are highly reliable and specific, they tend to be lengthy, costly and require the direct administration by a specialized clinician with expertise in psychological disorders. On the other hand, self-report measures, such as those used in the present study, are free, quick and easily accessible to any clinician, and can be completed by discharged patients from the comfort of their home. This can be an essential step in detecting the individuals at high risk, who can further be brought back to clinical attention for more advanced interviewing. One weakness of many previous studies in this area is that they have mostly been published in specialty psychiatry $(10)$ or critical care journals $(24,25,27)$. This has potentially limited the information dissemination to primary care providers, who will be following most of the patients after hospital
TABLE 2

Proportion of post-traumatic stress disorder (PTSD) according to instrument at three months postadmission to the intensive care unit

\begin{tabular}{lcc}
\hline Instrument & $\mathbf{n}$ & $\begin{array}{c}\text { With clinically relevant } \\
\text { PTSD symptoms, } \mathbf{n}(\%)\end{array}$ \\
\hline DTS $(\geq 40)$ & 69 & $23(33)$ \\
PTSS $(\geq 35)$ & 68 & $17(25)$ \\
IES Intrusions & 67 & $11(16)$ \\
IES Avoidance & 67 & $14(21)$ \\
\hline
\end{tabular}

DTS Davidson Trauma Scale; IES Impact of Event Scale; PTSS Posttraumatic Symptom Scale

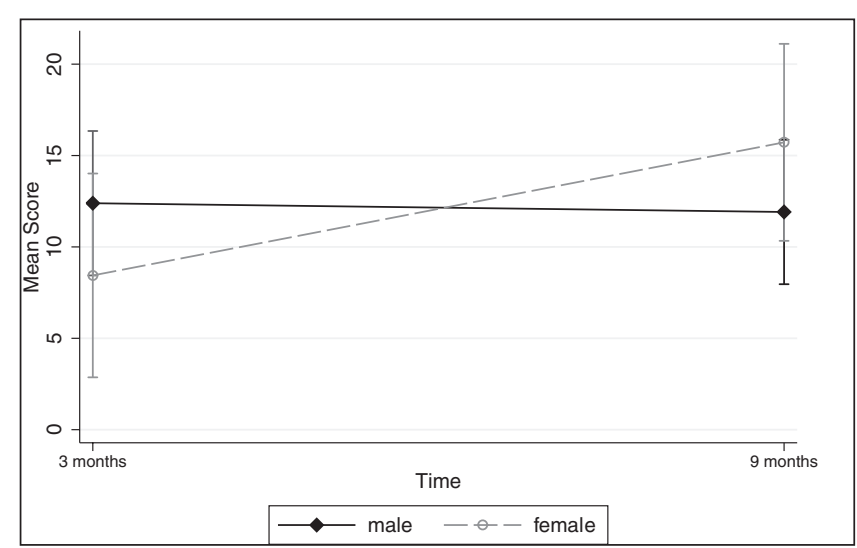

Figure 2) Time plot of Davidson Trauma Scale Hyperarousal scores according to sex

discharge, and to whom the responsibility for PTSD screening will likely fall. Steps to promote the awareness of ICU-related PTSD have included the establishment of the Intensive Care Outcome Network in the United Kingdom, whose aim is to measure long-term psychological outcomes of ICU treatment (28). A similar initiative could be undertaken in Canada.

The differential time course of symptoms according to sex in the current study has been inconsistently observed in previous studies. Although it is known that females are more susceptible to PTSD (29), ICU-related PTSD studies have drawn conflicting conclusions regarding the prognostic value of sex. Perrins et al (30) found that over a 12-month follow-up, male PTSD symptoms declined while those of females increased. Two additional studies $(31,32)$ found that women tend to have higher PTSD scores at follow-up (two months in one study and six months in the other) but change over time was not studied. Conversely, two different studies $(5,33)$ conducted shortly after hospital discharge found no association of PTSD symptoms with sex. Clearly the question of sex interaction with PTSD symptoms is an important one and will need to be addressed by future work in this area.

The present study had several limitations, the most obvious being the low rate of participation. The high attrition rate potentially introduced bias in the results and limits the ability to generalize them to all patients discharged from ICU. Participation may have been increased

TABLE 3

Proportion and mean scores for the subset of followed respondents $(n=37)$

\begin{tabular}{|c|c|c|c|c|c|}
\hline \multirow[b]{2}{*}{ Instrument } & \multirow[b]{2}{*}{$\mathbf{n}$} & \multirow{2}{*}{$\begin{array}{c}\text { Three months } \\
\text { post-ICU admission, } \mathrm{n}(\%)\end{array}$} & \multicolumn{3}{|c|}{ Nine months } \\
\hline & & & Mean $(95 \% \mathrm{CI})$ & post-ICU admission, $\mathrm{n}(\%)$ & Mean $(95 \% \mathrm{CI})$ \\
\hline DTS $(\geq 40)$ & 37 & $12(32)$ & 31.21 (20.48 to 41.95$)$ & $14(38)$ & 33.97 (22.70 to 45.25$)$ \\
\hline PTSS ( $\geq 35)$ & 37 & $7(19)$ & $23.58(18.86$ to 28.31$)$ & $10(29)$ & 26.06 (20.91 to 31.20$)$ \\
\hline IES Intrusions & 36 & $5(14)$ & 7.42 (4.14 to 10.69$)$ & $3(8)$ & $7.22(4.10$ to 10.34$)$ \\
\hline IES Avoidance & 36 & $6(17)$ & 7.89 (4.49 to 11.28$)$ & $8(22)$ & $8.17(4.39$ to 11.95$)$ \\
\hline
\end{tabular}

DTS Davidson Trauma Scale; ICU Intensive care unit; IES Impact of Event Scale; PTSS Post-traumatic Symptom Scale 
if subjects were enrolled in person before hospital discharge. However, the present study was unfunded and was not resourced for such a rigorous recruitment protocol. Furthermore, the absence of a detailed and standardized psychiatric history before ICU admission may have contributed to a more robust data set. Service delivery characteristics in the ICU, such as mechanical ventilation, were similarly unavailable and, therefore, cannot rule out the possibility that the delayed onset of PTSD symptoms in women was impacted by these factors. Additionally, the attrition rate between the first and second sampling time was quite high $(46 \%)$. While the high dropout rate is comparable with other PTSD-ICU studies, in the current study it mandated a simplification of the analysis of medication influence into the dichotomy of 'on psychotropic medication' or 'not on psychotropic medication.' The potential role of medication use in either identifying or contributing to the risk of developing PTSD symptoms raises a very interesting and important question, but one that will require a larger and more rigorous study to be properly answered. In the same way, inferences cannot be made with respect to the higher proportion of surgical and trauma cases among those lost to follow-up at nine months. If the dropout rate is related to the severity of PTSD, perhaps future studies can better address this limitation.

Despite its limitations, the current study does provide additional evidence to support early screening for psychological trauma induced by admission to the ICU. Daily diaries kept by ICU staff have been shown to be helpful in decreasing PTSD levels for both patients and relatives by helping patients to establish a sense of coherence

\section{REFERENCES}

1. American Psychiatric Association. Diagnostic and Statistical Manual of Mental Disorders, IV edn. Washington, DC: American Psychiatric Association, 2000.

2. Lew HL, Otis JD, Tun C, Kerns RD, Clark ME, Cifu DX. Prevalence of chronic pain, posttraumatic stress disorder, and persistent postconcussive symptoms in OIF/OEF veterans: Polytrauma clinical triad. J Rehab Res Dev 2009;46:697-702.

3. Wohlfarth TD, van den Brink W, Winkel FW, ter Smitten M. Screening for posttraumatic stress disorder: An evaluation of two self-report scales among crime victims. Psychological Assess 2003;15:101-9.

4. Andrykowski MA, Cordova MJ, Studts JL, Miller TW. Posttraumatic stress disorder after treatment for breast cancer: Prevalence of diagnosis and use of the PTSD Checklist-Civilian Version (PCL-C) as a screening instrument. J Consult Clin Psychol 1998;66:586-90.

5. Cuthbertson BH, Hull A, Strachan M, Scott J. Post-traumatic stress disorder after critical illness requiring general intensive care. J Intensive Care Med 2004;30:450-5.

6. Nickel M, Leiberich P, Nickel C, et al. The occurrence of posttraumatic stress disorder in patients following intensive care treatment: A cross-sectional study in a random sample. J Intensive Care Med 2004;19:285-90.

7. Eddleston JM, White P, Guthrie E. Survival, morbidity, and quality of life after discharge from intensive care. Crit Care Med 2000;28:2293-9.

8. Kapfhammer HP, Rothenhausler HB, Krauseneck T, Stoll C, Schelling G. Posttraumatic stress disorder and health-related quality of life in long-term survivors of acute respiratory distress syndrome. Am J Psychiatry 2004;161:45-52.

9. Hatch R, McKechnie S, Griffiths J. Psychological intervention to prevent ICU-related PTSD: Who, when and for how long? Crit Care 2011;15:141.

10. Bienvenu OJ, Neufeld KJ. Post-traumatic stress disorder in medical settings: focus on the critically ill. Curr Psychiatry Rep 2011;13:3-9.

11. O'Donnell ML, Creamer M, Holmes AC, et al. Posttraumatic stress disorder after injury: Does admission to intensive care unit increase risk? J Trauma 2010;69:627-32.

12. Wade DM, Howell DC, Weinman JA, et al. Investigating risk factors for psychological morbidity three months after intensive care: A prospective cohort study. Crit Care 2012;16:R192.

13. Davydow DS, Gifford JM, Desai SV, Needham DM, Bienvenu OJ. Posttraumatic stress disorder in general intensive care unit survivors: A systematic review. Gen Hosp Psychiatry 2008;30:421-34. regarding their ICU experience $(34,35)$. One suggestion is for the implementation of diaries to routine ICU practice as a relatively straightforward and low-cost initiative to help mitigate the psychological stress induced by an ICU admission. Another consideration is for physicians who provide outpatient follow-up care of ICU patients to include screening for PTSD symptoms as part of routine assessment. Simple screening tools could include the questionnaires applied in the current study: DTS, PTSS and the revised IES $(36,37)$. The obvious potential benefit is that patients who screen positively for PTSD symptoms could then be targeted for appropriate intervention. Better communication between ICU medical specialists and the patient's family is also recommended because this has been shown to be important to the well-being of families and patients (38). Finally, a nationwide ICU database in Canada - perhaps modelled after the RECOVER program at the University of Toronto (Toronto, Ontario) - may be a valuable resource because this would provide more evidence-based data regarding risks for post-ICU PTSD and inform potential interventions.

\section{CONCLUSION}

We demonstrated a high rate of PTSD symptoms in survivors of admission to the ICU. These symptoms appear to follow a protracted course that may differ according to sex. The adoption of screening tools and a multicentre ICU database in Canada is recommended to identify patients most at risk for PTSD symptoms.

14. Rattray JE, Johnston M, Wildsmith JA. Predictors of emotional outcomes of intensive care. Anaesthesia 2005;60:1085-92.

15. Toien K, Myhren H, Bredal IS, Skogstad L, Sandvik L, Ekeberg O. Psychological distress after severe trauma: A prospective 1-year follow-up study of a trauma intensive care unit population. J Trauma 2010;69:1552-9.

16. Davidson JR, Book SW, Colket JT, et al. Assessment of a new selfrating scale for post-traumatic stress disorder. Psychol Med 1997;27:153-60.

17. Brewin CR. Systematic review of screening instruments for adults at risk of PTSD. J Trauma Stress 2005;18:53-62.

18. Horowitz M, Wilner N, Alvarez W. Impact of Event Scale: A measure of subjective stress. Psychosom Med 1979;41:209-18.

19. Joseph S. Psychometric evaluation of Horowitz's impact of event scale: A review. J Trauma Stress 2000;13:101-13.

20. Adkins JW, Weathers FW, McDevitt-Murphy M, Daniels JB. Psychometric properties of seven self-report measures of posttraumatic stress disorder in college students with mixed civilian trauma exposure. J Anxiety Disord 2008;22:1393-402.

21. Bienvenu OJ, Williams JB, Yang A, Hopkins RO, Needham DM. Posttraumatic stress disorder in acute lung injury survivors: Evaluating the impact of event scale-revised. Chest 2013;144:24-31.

22. Stoll C, Kapfhammer HP, Rothenhausler HB, et al. Sensitivity and specificity of a screening test to document traumatic experiences and to diagnose post-traumatic stress disorder in ARDS patients after intensive care treatment. Intens Care Med 1999;25:697-704.

23. Davidson JR, Tharwani HM, Connor KM. Davidson Trauma Scale (DTS): Normative scores in the general population and effect sizes in placebo-controlled SSRI trials. Depress Anxiety 2002;15:75-8.

24. Jones C, Griffiths RD, Humphris G, Skirrow PM. Memory, delusions, and the development of acute posttraumatic stress disorder-related symptoms after intensive care. Crit Care Med 2001;29:573-80.

25. Jones C, Skirrow P, Griffiths RD, et al. Rehabilitation after critical illness: A randomized, controlled trial. Crit Care Med 2003;31:2456-61.

26. Sukantarat K, Greer S, Brett S, Williamson R. Physical and psychological sequelae of critical illness. Br J Health Psychol 2007;12:65-74.

27. Jones C, Backman C, Capuzzo M, et al. Intensive care diaries reduce new onset post traumatic stress disorder following critical illness: A randomised, controlled trial. Crit Care 2010;14:R168.

28. Griffiths JA, Morgan K, Barber VS, Young JD. Study protocol: The Intensive Care Outcome Network ('ICON') study. BMC Health Serv Res 2008;8:132. 
29. Stein MB, Walker JR, Forde DR. Gender differences in susceptibility to posttraumatic stress disorder. Behav Res Ther 2000;38:619-28.

30. Perrins J, King N, Collings J. Assessment of long-term psychological well-being following intensive care. Intens Crit Care Nurs 1998;14:108-16.

31. Samuelson KA, Lundberg D, Fridlund B. Stressful memories and psychological distress in adult mechanically ventilated intensive care patients - a 2-month follow-up study. Acta Anaesthesiol Scand 2007;51:671-8.

32. Girard TD, Shintani AK, Jackson JC, et al. Risk factors for posttraumatic stress disorder symptoms following critical illness requiring mechanical ventilation: A prospective cohort study. Crit Care 2007;11:R28.

33. Talisayon R, Buckley T, McKinley S. Acute post-traumatic stress in survivors of critical illness who were mechanically ventilated: A mixed methods study. Intens Critical Care Nurs 2011;27:338-46.
34. Garrouste-Orgeas M, Coquet I, Perier A, et al. Impact of an intensive care unit diary on psychological distress in patients and relatives. Crit Care Med 2012;40:2033-40.

35. Engstrom A, Grip K, Hamren M. Experiences of intensive care unit diaries: 'Touching a tender wound'. Nurs Crit Care 2009;14:61-7.

36. Twigg E, Humphris G, Jones C, Bramwell R, Griffiths RD. Use of a screening questionnaire for post-traumatic stress disorder (PTSD) on a sample of UK ICU patients. Acta Anaesthesiol Scand 2008;52:202-8.

37. Beck JG, Grant DM, Read JP, et al. The impact of event scalerevised: Psychometric properties in a sample of motor vehicle accident survivors. J Anxiety Disord 2008;22:187-98.

38. Davidson JE, Jones C, Bienvenu OJ. Family response to critical illness: Postintensive care syndrome-family. Critical Care Med 2012;40:618-24. 


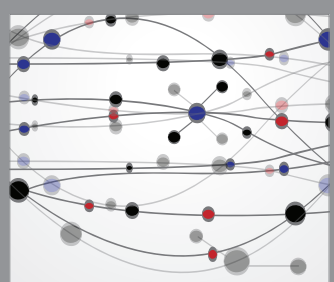

The Scientific World Journal
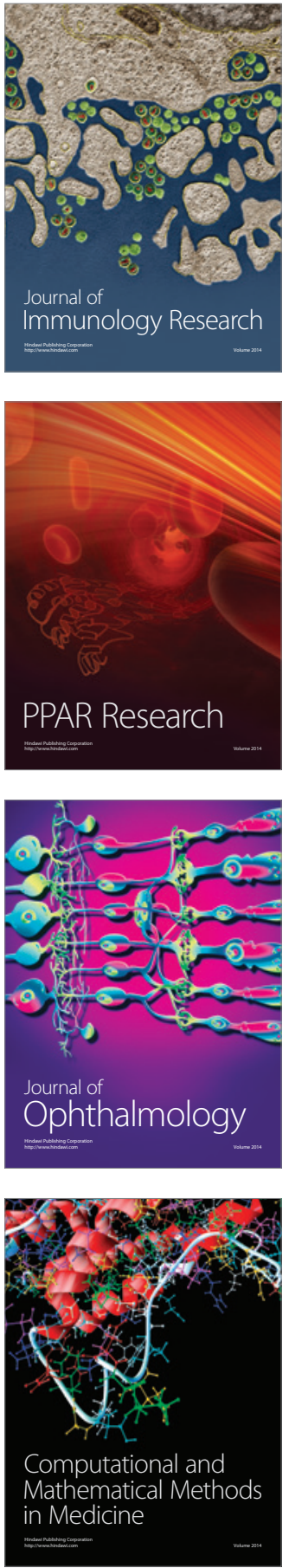

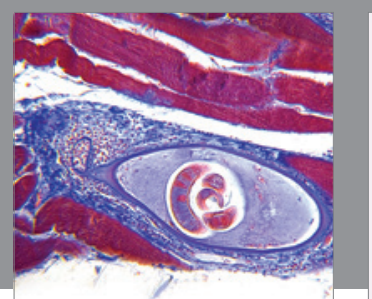

Gastroenterology Research and Practice

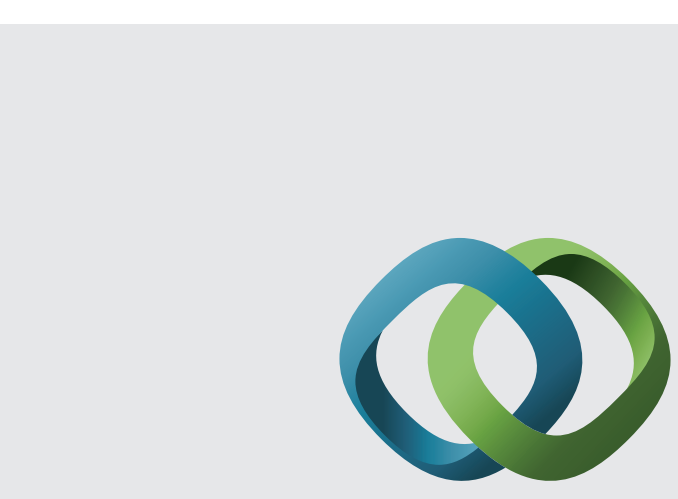

\section{Hindawi}

Submit your manuscripts at

http://www.hindawi.com
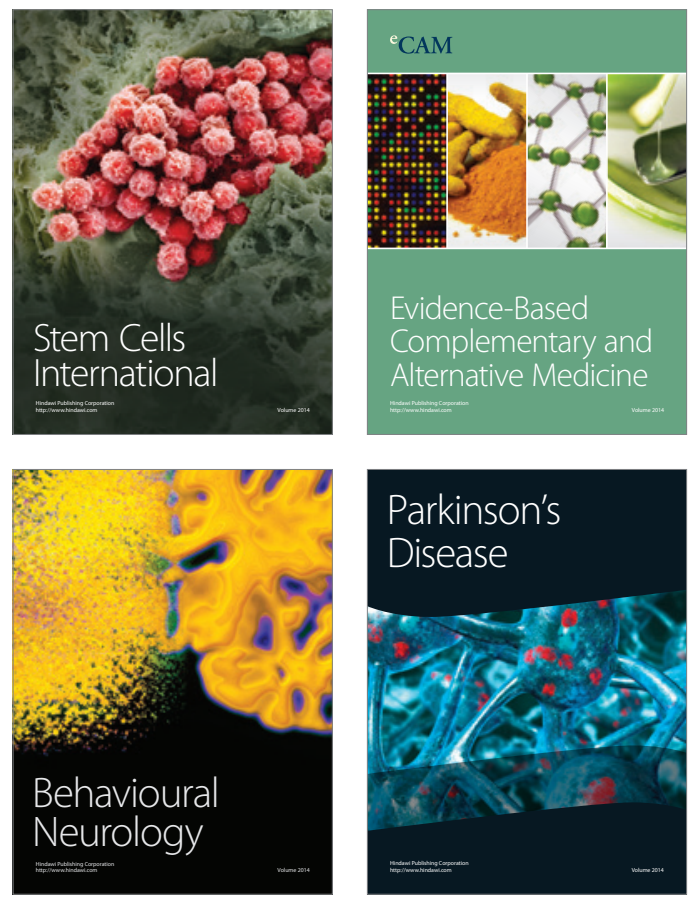
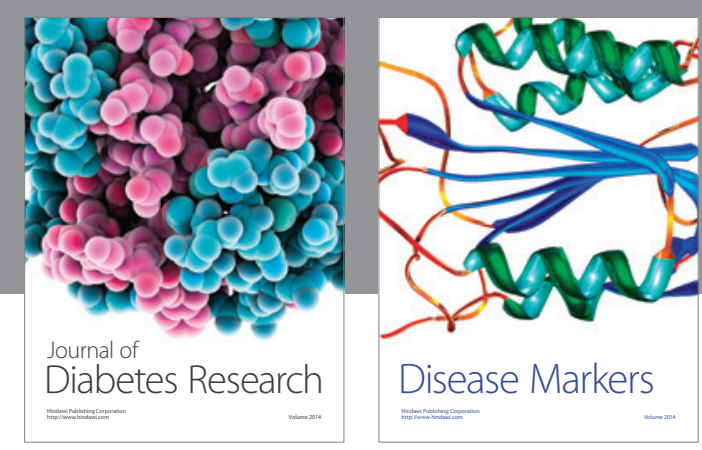

Disease Markers
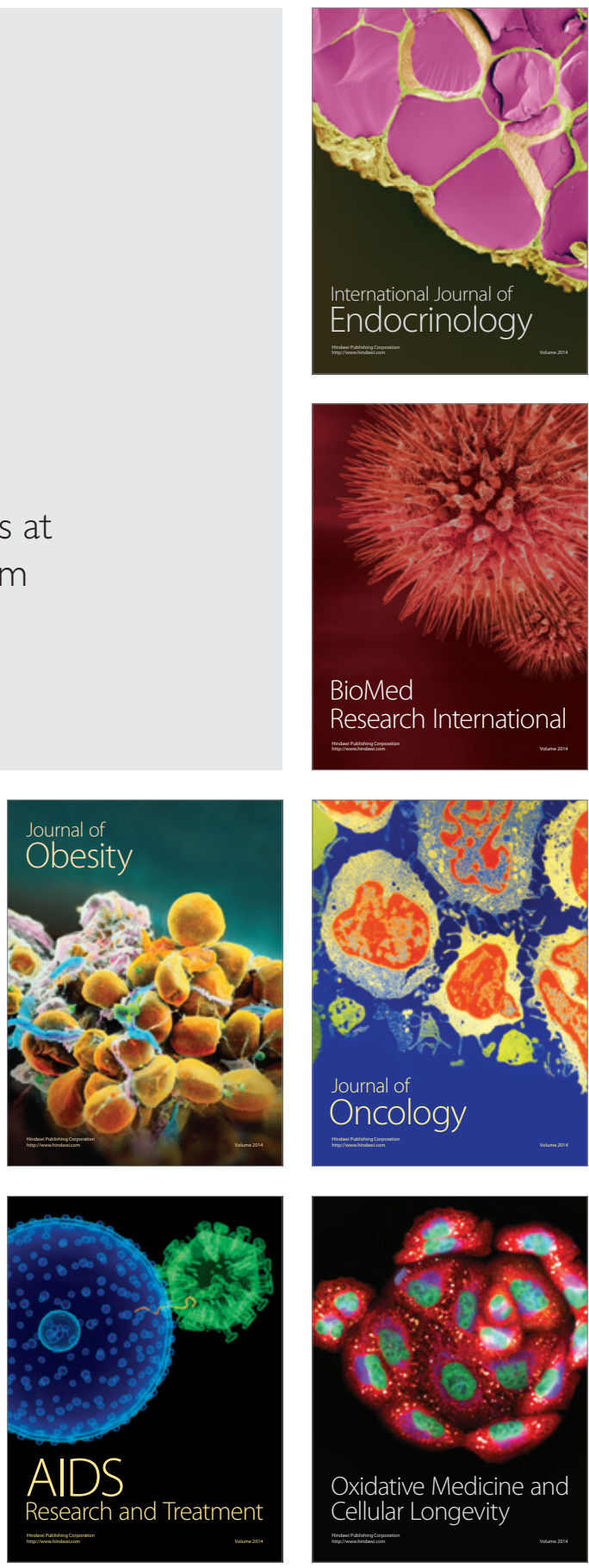